\section{Learning Spanish Today}

A Research Guide

\section{Andrew Walsh, Guest Columnist}

Correspondence concerning this column should be addressed to Neal Wyatt, The Alert Collector, c/O RUSA, 50 E. Huron, Chicago, IL 60611; alertcollector@comcast .net. Wyatt is a collection development and readers' advisory librarian from Virginia. She wrote The Readers' Advisory Guide to Nonfiction (ALA Editions, 2007), is the editor of Library Journal's "Reader's Shelf" column, author of Booksmack!'s "RA Crossroads" whole collection RA column, and compiles LJ's weekly "Wyatt's World Lists."

Andrew Walsh is enrolled in the master's degree program in library and information science at the University of Illinois at Urbana-Champaign.
Learning a foreign language is of constant interest-to students, travelers, lifelong learners, and job seekers. The landscape of such study, once offered only through a small selection of cursory guides and complicated audio courses, has radically changed. Now students can get the basics for free online, learn in conversations with native speakers in social media communities, and have access to a rich world of print and electronic resources that are exhaustive in their coverage. Andrew Walsh, a Graduate Assistant at the Literatures and Languages Library at the University of Illinois UrbanaChampaign and a master's student in Library and Information Science there, has written a guide to help librarians, be they in large academic institutions, public libraries, or high-school libraries, develop a modern collection of resources to aid the language learner. Walsh holds a bachelor's degree in Spanish and has enjoyed studying the language since his elementary school days and thus has great experience with the tools that really help one learn. While his guide is dedicated to resources for the Spanish language, it also serves as a model for those seeking to build collections in other languages-highlighting the types of tools available and suggesting the kinds of resources that create the most useful collections.-Editor

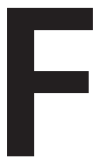

oreign language education is in the midst of a radical transformation, fueled by a boom of new technologies and applications for learning. Today, educational institutions are including more digital and interactive media alongside textbooks and traditional resources as they recognize the value of information technology. But what is the right balance? Videos, podcasts, interactive online games and quizzes are very effective for some purposes while printed books remain far superior for others. Existing guides in this area are typically either bibliographies of print material or informal lists of online websites. Rarely does either style of guide compare the different types of tools, which makes identifying the best resources a difficult proposition. Additionally, the highly commercial nature of the web makes finding quality resources through Internet searches extremely difficult, as most websites are trying to make a profit from advertisements, sales of their own products or affiliate commissions.

This column recommends print textbooks, grammar books and reference books while also comparing them to newly emerging formats in an attempt to paint a more complete picture of the ways Spanish is learned today. The resources were selected based on their usefulness, scope, methods, organization and clarity. Sources that address cultural realities and regional variations are highlighted, since Spanish has such diverse dialects and varieties across Iberia and Latin America. The sources included are bilingual. Advanced learners will want to consult monolingual resources as well. Of course, many other valuable resources exist beyond those listed in this work, but my purpose is to give collection development librarians a good 


\section{THE ALERT COLLECTOR}

starting point to build a collection based upon a group of core resources for each category. A title's exclusion from this list does not signify that it is not valuable.

The target learning group for this collection of resources is college-level learners of Spanish, which means that advanced high school students as well as older adults can benefit as well. A short introductory section first lists a selection of quick resources designed to provide a fast and easy start to learning Spanish. Then the bulk of the guide is organized in categories based on the type of resource.

Note: All online resources were accessed on 4/29/11.

\section{QUICK RESOURCES FOR BEGINNING SPANISH}

Between online lessons, podcasts and affordable basic language textbooks, there are plenty of ways for a beginner to get a quick introduction to the Spanish language at little to no cost. A variety of organizations provide free language instruction online, with various types of lessons typically geared toward beginners. This learning format has several advantages: there are often convenient features such as e-mail newsletters for delivery of new lessons, blogs with updated posts, and a "word of the day" or similar content. There are often exercises and quizzes, and answers are graded immediately so that the learner can determine areas that need additional focus. Here are a few of the most effective ways to get started with Spanish. (A more comprehensive list of free online resources is found later in the Online Resources section.)

\section{Websites}

BBC Languages: Spanish (www.bbc.co.uk/languages/spanish).

The $\mathrm{BBC}$ language page offers a variety of free activities for beginners. There are informative guides to introduce the language, as well as many lessons that combine grammatical exercises with interactive video content. Learners can sign up for a complete twelve-week "Spanish Steps" beginner's course in which weekly lessons will be delivered via e-mail. For those learners looking to move up to intermediate level, there is a quiz designed to gauge your current Spanish level.

Más Arriba: Spanish Language Exercises (www.trentu.ca/ academic/modernlanguages/spanish/masarriba).

Gary Aitken, a retired professor of Spanish at Trent University in Ontario, Canada, has put together this great collection of Spanish language exercises. The content includes audio clips from native speakers and pictures which accompany written activities.

Coffee Break Spanish Podcast (http://radiolingua.com/shows/ spanish/coffee-break-spanish)

An award-winning free Spanish course delivered through podcasts. The weekly 15-20 minute lessons focus on realworld situations, culture and learning effective communication skills. For those listening to the lessons from the Radio
Lingua website, be sure to navigate to the free audio lessons as there is also a paid premium course with additional materials. Users of Apple's iTunes will find it much easier to subscribe to the podcast by searching the iTunes store.

\section{Books}

Living Language. Starting out in Spanish. New York: Living Language, 2008 (ISBN: 978-1-4000-2462-9).

For learners who want a slightly more formal lesson-bylesson approach but prefer the audio format, this affordable course can be a great resource. It features a variety of dialogues and lessons over three CDs. Several different native speakers provide the narration, with complete transcripts available online. The format is also ideal for busy learners who wish to learn Spanish on the go.

Berlitz Publishing Company. 5-Minute Spanish. New York: Berlitz, 2009. (ISBN: 978-9-8126-8456-1).

A simple way to get started with Spanish on your own, this beginner's book features fun lessons that take only about five minutes to complete, hence the title. Activities teach basic grammatical points and introduce cultural themes. The book integrates text with images and audio, and the course also includes a free CD with native speaker audio and Internetbased resources.

\section{IN-DEPTH RESOURCES FOR SPANISH LEARNERS BY CATEGORY}

\section{Online Resources}

\section{Reference Tools}

When all that is required is a simple lookup of a word, online reference resources have surpassed their print counterparts in terms of convenience without sacrificing authority. They feature definitions taken from respected dictionaries and often offer additional services print resources do not, including message boards, sentence translation, and easy mechanisms for finding related entries. There are also online Spanish verb conjugation tools that save a lot of time. The following have been selected as the most useful.

WordReference.com Dictionary (www.wordreference.com/ English_Spanish_Dictionary.asp).

Offers two free dictionaries, the Concise Oxford Spanish Dictionary (2005) and the Diccionario Espasa Concise (2000). The Oxford dictionary has over 100,000 words and 200,000 translations. It also features several support features and mechanisms for finding related entries in both Spanish and English.

SpanishDict Dictionary (www.spanishdict.com)

Takes definitions from the Webster's New World Concise Spanish Dictionary, and offers a phrasebook and answers forum alongside traditional entries. The dictionary also has 
optional features such as flashcards and a word of the day email newsletter. Also has a translation tool for longer chunks of text that queries the three top translation engines: Google Translate, Freetranslation and Babel Fish. These services can be imprecise and unreliable, however, so this feature should be used with caution.

Conjugation.org: Spanish Verb Conjugations (www.conjuga tion.org).

Helpful online tool for conjugating Spanish verbs. Type in the infinitive form of the verb to instantly see conjugations in either table or list format. Also has an option to show or hide pronouns as well as conjugate only certain tenses. Features a very simple and easy to use interface.

\section{Online Lessons and Courses}

In recent years, many companies, educators and private entrepreneurs have created a wide variety of free online Spanish language lessons. Some are as simple as a basic introduction to grammar or vocabulary while others are comprehensive language courses complete with multimedia activities. There are plenty of great resources to be found on the web, but this category requires extremely careful evaluation. Simply browsing in a search engine leads to problems, including the masses of low-quality sites that offer a small amount of information plastered with advertisements. Many others offer one or two lessons as a teaser to try to get users to purchase their products, which are of much lower quality than the resources in this research guide. To determine which free online Spanish language resources are valuable, it is necessary to evaluate the author's identity, his or her affiliation, and the amount and quality of language learning information. The following have been selected as the most useful.

BBC Languages: Spanish (www.bbc.co.uk/languages/spanish).

An impressive and varied collection of Spanish resources, including free audio and video courses, worksheets, quizzes and e-mail newsletters that put lessons directly in your inbox. Includes many sections designed for intermediate learners, and also provides tips for learning the language by using Spanish media.

About.com Spanish Language (http://spanish.about.com).

Another diverse collection of resources written by a full-time Spanish specialist, Gerald Erichsen, the About. com Spanish website offers many different ways to learn. It has a five-unit online Spanish course for beginners and a wealth of lessons and articles for intermediate learners, covering the most important issues in grammar, vocabulary, usage and more. Also features a variety of pages related to culture and a frequently updated blog that puts a more personal touch on learning the language. There are many ways to interact with the site, such as blog comments and a language forum.
Spanish Language and Culture (www.colby.edu/ bknelson/SLC).

The personal website of Barbara Kuczun Nelson, Spanish professor at Colby College, Spanish Language and Culture offers an impressive assortment of grammar activities and exercises, often with audio. There are also study modules that integrate language and culture, including guided readings of Spanish-language songs and poems, as well as videos that help teach grammatical structures.

The Spanish Blog (www.thespanishblog.com).

Created by Laura Garrido Eslava, a Spanish language teacher in Bilbao, Spain, this website provides a variety of ways to learn both Spanish language and culture. Video lessons cover pronunciation, verb tenses and related grammatical structures. The wealth of cultural information and activities, however, provide the bulk of the website's value and are extremely helpful for all learners interested in Spain. There are detailed city guides for each major city, a variety of Spanish recipes as well as articles about the history of the country. Language and culture come together in the television and music sections of the website, as links are provided to watch full episodes of Spanish TV shows. The music pages offer embedded videos of popular songs with accompanying lyrics, featuring artists from both Spain and Latin America.

Spanish Blog: Language and Culture of the Spanish Speaking World (www.transparent.com/spanish).

This website, put together by software company Transparent Language, offers many different types of content to help learners. It has a staff of several different writers who use lessons, videos and even cultural anecdotes and essays written in Spanish to teach grammar, vocabulary, pronunciation and culture. The blog's strength is in its versatility: learners can sign up to receive posts via e-mail, Facebook, Twitter and RSS. In addition to the blog updates, there are additional Spanish lessons and free software if you opt into their e-mail list.

\section{Online Social Communities}

These resources are all available online, but compared to the previous section, these are more social and are designed primarily to connect different learners to ask questions and help each other learn. In the last few years, several companies have started to harness the power of the social web to create a radically different model of web-based language learning, one that is based on real interactions with native speakers and focused on learning how to communicate effectively. This category also includes language forums, which have been around for many years. Most forums are offered in conjunction with other resources, such as online Spanish dictionaries, but for the purposes of this section, they are being evaluating as standalone entities.

Wordreference.com Language Forums (http://forum.wordref erence.com).

The Wordreference forums are by far the most active in the world, with roughly 20,000 active members. Users can 


\section{THE ALERT COLLECTOR}

ask a question about the Spanish language or search through the thousands of archived topics. A select group of native speakers serve as moderators, and the authority of posters is ensured by a system of reputation. There are sub-forums for Spanish/English vocabulary, grammar and specialized terms, and every appropriate question that is posed receives answers by experienced speakers.

Tomisimo Spanish Langauge Learning Forums (http://forums .tomisimo.org).

This forum operates under the same system as Wordreference, but it is exclusive to Spanish and features several additional sub-forums. In addition to those dedicated to vocabulary and grammar, there are forums for translation, practice, cultural differences and even teaching methodologies.

Livemocha (www.livemocha.com/learn-spanish).

Livemocha is the largest of the online language social networks, an exciting new breed of language learning resource that stresses real communication and facilitates connections between learners and native speakers of 35 languages, including Spanish. There are some free interactive language lessons that stress communication skills, but the real value comes from interactions with other members. Learners submit their exercises and even voice recordings and receive corrections and feedback from native speakers. There is also an opportunity to live chat with other members, a great way to practice conversational Spanish. The learning model for this type of website is reciprocal, and members who are learning Spanish are expected to help English learners. To encourage this, there is a point system that eventually leads to access to premium language material.

Lenguajero (http://lenguajero.com).

Unlike the larger Livemocha website, Lenguajero is a community exclusively for Spanish and English learners, which makes it much easier to connect with others. It has systems for flashcard learning and writing exercises, but it also offers a feature where members can record and upload podcasts to be voted on by the community. It is much easier to find a chat partner on Lenguajero, as it is only for learners of Spanish and English and learners will never be approached by someone who speaks a language other than Spanish as is frequently the case with Livemocha.

\section{PRINT RESOURCES}

\section{Dictionaries/Reference Sources}

While online reference sources earn praise for their convenience, the benefits of print reference come from their exhaustive coverage. The free online tools are quite limited in scope, as the top unabridged print dictionaries typically contain at least three times the number of entries of their online counterparts. Other useful resources that cannot be found on the web include dictionaries for particular regions and varieties of Spanish, specialized dictionaries for particular types of words or parts of speech and illustrated dictionaries.

Galimberti, Jarman B., Roy Russell, Carol S. Carvajal, and Jane Horwood. The Oxford Spanish Dictionary. New York: Oxford Univ. Pr., 2008 (ISBN: 978-0-1992-0897-5).

Widely considered the most complete Spanish-English dictionary on the market, the fourth edition contains over 300,000 words and 500,000 translations. It has been updated to include the latest colloquialisms, buzzwords and specialized vocabulary. Covers 24 different regional varieties of Spanish and includes numerous cultural notes.

Galván, Roberto, A., and Richard V. Teschner. The Dictionary of Chicano Spanish: El Diccionario Del Español Chicano. Lincolnwood, Ill.: National Textbook, 1995 (ISBN: 978-08442-7966-4).

Although it dates back to 1995, this is still a valuable resource for those interested in learning the particularities of the Chicano Spanish variety spoken in the United States. It contains over 9,000 words and phrases.

Hamel, Bernard H. Hamel's Comprehensive Bilingual Dictionary of Spanish False Cognates: Gran Diccionario De Términos Equivicos Del Inglés. Los Angeles: Bilingual Book Pr., 1998 (ISBN: 978-1-8868-3506-1)

False cognates, words that appear to be similar in Spanish and English but really hold different meanings, are a source of frustration for many learners. This bilingual dictionary has separate sections for Spanish and English, and with over 2,000 false cognates and 10,000 definitions, it is a very comprehensive work.

Richmond, Dorothy Devney. Guide to Spanish Suffixes. Lincolnwood, Ill.: Passport Books, 1992 (ISBN: 978-0-8442-7323-5).

An excellent strategy for increasing vocabulary is to study the common endings of Spanish words. This unique work covers hundreds of suffixes and includes a complete index for quick reference. It also points out general equivalencies in Spanish and English suffixes to help broaden the learner's understanding.

The Oxford-Duden Pictorial Spanish-English Dictionary. New York: Oxford Univ. Pr., 1995 (ISBN: 978-0-1986-4515-3).

For more visual learners, as well as those interested in learning particularly specific or technical vocabulary, this dictionary is a great resource. For certain concepts that are complicated to explain, it is much more effective to see definitions in pictorial format. There are over 28,000 objects accompanied by illustrations, spanning many diverse subjects, and each picture has English and Spanish words on the same page.

Olivares, Rafael A. NTC's Dictionary of Latin American Spanish. Lincolnwood, Ill.: NTC Pub. Gr., 2000 (ISBN: 978-0-84427964-0).

A helpful dictionary divided into sections for 19 different 
Latin American countries, covering over 6,000 words specific to those nations' varieties of Spanish. There is room for improvement, however, as some words lack important contextual information, but the book thoroughly represents all Latin American countries and at the moment is still the most valuable resource of its kind.

\section{Textbooks}

Traditionally, the most common way to learn Spanish is the textbook, and this is still the case even with all of the new methods that have emerged. In general, textbooks are the best format for learning grammar, vocabulary and culture all at one time, and they contain supplemental activities carefully crafted to help students commit each chapter's material to long-term memory. There are numerous reasons for libraries to add textbooks to their collections. They help disadvantaged students gain access to needed materials, and are very convenient for helping a large number of people, especially if put on reference only or short-term loan. Also, the simple fact that textbooks are the preferred format for student learning makes them a valuable resource to collect and make available for all learners. In this section I introduce the different categories of textbooks and discuss some of the popular titles.

Silverstein, Ruth J., Heywod Wald, and Allen Pomerantz. Spanish Now. Level 1. Hauppauge, N.Y.: Barron's, 2005 (ISBN: 978-0-7641-7774-3).

A very affordable beginner's textbook, updated in 2005 with the release of the seventh edition, which now includes an accompanying workbook and four CDs. It is geared toward learners with some previous Spanish familiarity, and its dialogues and exercises are lively, covering grammatical structure, instilling fundamentals of reading comprehension and depicting the cultures of both Spain and Latin America. It does not have as many companion features as the more expensive textbooks, but you get a lot for the price, and it is appropriate for individual learners.

Jarvis, Ana C., Raquel Lebredo, and Francisco Mena-Ayllón. ¿Como se Dice ... ? Boston: Heinle, Cengage Learning, 2011 (ISBN: 978-0-4959-0981-1).

The enhanced ninth edition of ¿Como se Dice? is heavily integrated with an online companion course. The series has been popular among high school and college instructors for years, and now includes many interactive activities online in addition to the lessons in the print book.

Knorre, Marty, Thalia Dorwick, and Ana María Pérez-Gironés. Puntos de Partida: An Invitation to Spanish. New York: McGrawHill, 2009 (ISBN: 978-0-0735-3442-8).

Another textbook frequently used by educators which has undergone a major redesign for this most recent eighth edition. Recognizing that language education is in a state of flux, the authors consulted over 250 teachers and students to identify appropriate changes to remain effective. As a result, several interesting digital components accompany the book.

Sandstedt, Lynn A., Ralph Kite, John G. Copeland, and John G. Copeland. Intermediate Spanish. Civilización y Cultura. Boston: Thomson/Heinle, 2008 (ISBN: 978-1-4390-8449-6).

A textbook designed for intermediate-level learners, this tenth edition structures its lessons thematically and integrates a wide variety of cultural activities to help advance students' language skills and give them valuable practical knowledge. This is accomplished through cultural essays and articles as well as videos.

Blanco, José A., and Philip Redwine Donley. Vistas: Introduccion a la Lengua Espãnola. Boston: Vista Higher Learning, 2007 (ISBN: 978-1-6000-7104-1).

Vistas is a newer textbook series, and in less than a decade it has solidified a place among the most frequently used texts in introductory Spanish courses. This third edition takes a student-centric approach-in addition to the lessons in the textbook, a complete accompanying website provides a variety of additional exercises and activities.

\section{Grammar and Usage Guides}

Textbooks provide a step-by-step approach to the Spanish language, but the fact that they must cover everything means they cannot go very far in depth on any particular aspect. It is also common for textbooks to make generalizations or simplify particular aspects of the language. For this reason, a strong collection of grammar and usage guides is critical to fill in the gaps.

Anderson, Gunnar. Colloquial Spanish in Context: Beyond Subjunctive Barriers. Lanham, Md.: Univ. Pr. of America, 2003 (ISBN: 978-0-7618-2656-9).

The subjunctive verb mood is extremely important in Spanish, and it is frequently cited as one of the most frustrating and confusing aspects of the language for Englishspeaking learners. This book tackles it in a unique way: it uses popular "Condorito" Chilean comic strips to introduce these tricky verb forms and all of their subtleties. The strips also do a great job of introducing important colloquial vocabulary and phrases, which are thoroughly explained afterward.

Batchelor, R. E., and José M. A. San. A Reference Grammar of Spanish. New York: Cambridge Univ. Pr., 2010 (ISBN: 9780-5217-2875-1).

A comprehensive reference work covering contemporary Spanish grammar, this book is extremely valuable for a wide variety of learners interested in the structure of the language. It is well organized and covers all major aspects of grammar in detail while remaining very clear and readable. The examples chosen to accompany the grammar points are effective, and the book also points out differences between the major regional varieties of Spanish. 


\section{THE ALERT COLLECTOR}

Batchelor, R. E. A Student Grammar of Spanish. New York: Cambridge Univ. Pr., 2006 (ISBN: 978-0-5111-4039-6).

This is a much more concise look at Spanish grammar than A Reference Grammar of Spanish, but it covers the same grammar topics including word order, verbs, syntax and gender, all supported by clear examples. The book is aimed at the college-level intermediate student who does not have explicit grammar background; it would be the perfect supplement for a motivated learner enrolled in an undergraduate course, or a valuable reference resource for an independent learner.

Batchelor, R. E., and Miguel Angel San José. Using Spanish Vocabulary. New York: Cambridge Univ. Pr., 2003 (ISBN: 978-0-5210-0862-4).

A thorough approach to learning vocabulary, this volume is organized into 20 different thematic units. Immediately following the lists of words in each section are exercises that reinforce the material and sharpen other relevant skills. Also includes specialized vocabulary in common areas. The book is explicit to note when particular words are particular to Iberian or Latin American Spanish, and it can be either read at length, consulted for reference or simply browsed for interest.

Burke, David. Street Spanish 1: The Best of Spanish Slang. New York: Wiley, 1997 (ISBN: 978-0-4711-7970-2).

This work introduces a significant amount of Spanish slang in a lively format with dialogues, word games and other activities. Covers the slang of several Spanish-speaking countries.

Keenan, Joseph J. Breaking Out of Beginner's Spanish. Austin, Tex.: Univ. of Texas Pr., 1994 (ISBN: 978-0-2927-4322-9).

Using a much different approach to learning Spanish, this book presents a more casual writing style than that found in most textbooks and has a pleasing personal voice. The material, however, is carefully selected and the most common problems that affect Spanish language learners are dissected. Serves as a refreshing change of pace from more formal academic books and provides indispensable knowledge for intermediate learners looking to take the leap to the next level.

Savaiano, Eugene, and Lynn W. Winget. Spanish Idioms. Barron's foreign language guides. Hauppauge, N.Y.: Barron's, 2007 (ISBN: 978-0-7641-3557-6).

This helpful guide lists roughly 2,500 Spanish idioms that are organized alphabetically by their keywords for easy reference. For each entry, there is both an English translation and a full sentence in Spanish to help fully illustrate meaning.

Richmond, Dorothy Devney. Practice Makes Perfect: Spanish Verb Tenses. Lincolnwood, Ill.: Passport Books, 2010 (ISBN: 978-0-0716-3930-9)

A unique resource for learning Spanish verbs. Simple print guides that solely provide lists of conjugations are quickly becoming replaced by free online tools, but this work does much more. There are thorough explanations for why certain verbs are used in certain situations as well as sections for each of the main tenses. Exercises are used to gauge comprehension, and this emphasis on practice is very helpful for learners who struggle with verbs. Practice Makes Perfect is a series that also offers volumes on grammar, pronouns and prepositions and more; all works are recommended.

Lipski, John M. Varieties of Spanish in the United States. Washington, D.C.: Georgetown Univ. Pr., 2008 (ISBN: 978-1-5890 -1213-4)

A detailed linguistic look into the diverse varieties of Spanish spoken in the United States, including Mexican, Cuban, Puerto Rican, Dominican and several Central American varieties of Spanish. Provides significant historical context, a background of the general development, and an overview of scholarship that has been produced on Spanish in the United States. It can be difficult for students with no previous experience in linguistics, although this can be remedied with some brief background research.

Lipski, John M. Latin American Spanish. New York: Longman, 1994 (ISBN: 978-0-5820-8760-6).

For learners interested in the different varieties of Spanish in Latin America, this book is a great supplement to textbooks and other types of language courses. Similar to Varieties of Spanish in the United States, this work is linguistic in its analysis, and readers should have at least a basic knowledge of some of this terminology. It is not the case, however, that this scope hurts the book's practical value; on the contrary, it helps paint a much more complete picture of Spanish as it is actually spoken than is possible in any textbook. 